Jo Bardoel*

\title{
Journalistiek moet zich durven onderscheiden
}

\author{
TOEKOMST VOOR DE PROFESSIE IN EEN MULTIMEDIALE OMGEVING
}

\begin{abstract}
Met de overgang van industriële naar 'netwerkjournalistiek' worden de media-instituties die per traditie de kwaliteit en onafhankelijkheid van de professie waarborgden minder belangrijk. De garantie voor adequaat journalistiek handelen verschuift daardoor van de mediaorganisatie naar de individuele professional. Om in een open multimediale omgeving te kunnen overleven, zal de journalistiek zich meer moeten professionaliseren en scherper profileren.
\end{abstract}

\section{Inleiding}

Een themanummer van dit tijdschrift over journalistiek en journalism studies; wie had dat tien, vijftien jaar geleden durven denken? Deze academische erkenning komt ruim honderd jaar na het eerste opleidingsdebat en een kleine halve eeuw na de oprichting van de eerste voltijdse opleiding in de journalistiek (Hemels, I972; Bardoel, I993). In dit verband veelzeggender is wellicht het feit dat journalistiek in de laatste twintig jaar een academische discipline geworden is, met naast onderwijs ook aandacht voor onderzoek. Toen tien jaar geleden een initiatiefgroep vanuit de KNAW-commissie Bevordering Mediahistorisch Onderzoek een academische conferentie organiseerde over de stand van het onderzoek naar de journalistiek in ons land - achteraf geboekstaafd in Journalistieke Cultuur in Nederland (Bardoel et al., 2002) - kwamen de bijdragen van alle kanten, maar vooral van sociale en geesteswetenschappers alsook van journalisten zelf. Uit dit themanummer mag blijken dat in het afgelopen decennium zowel de schaal als de coherentie van journalism studies dankzij een sterkere verankering aan de academie aanzienlijk is toegenomen.

\footnotetext{
Jo Bardoel is hoogleraar Journalistiek en Media aan de Radboud Universiteit Nijmegen. Daarnaast is hij ook deeltijds verbonden aan de afdeling Communicatiewetenschap en de Amsterdam School of Communication Research (ASCoR), beide aan de Universiteit van Amsterdam. Hij doet onderzoek naar en publiceert over mediabeleid en journalistiek.Correspondentieadres: Kloveniersburgwal 48, ıог2 CX Amsterdam. Tel: 020-5253917/024-361372, e-mail: j.bardoel@maw.ru.nl; j.l.h.bardoel@uva.nl.
} 
Deze erkenning van en canonisering door de wetenschap markeert een belangrijk moment, maar is evenmin vrij van risico's. Als we terugkijken binnen ons eigen domein, de sociale wetenschappen, dan zien we dat de perswetenschap pas goed op gang kwam toen, halverwege vorige eeuw, de krant moest inschikken ten behoeve van andere media zoals de radio en de televisie. En de televisiewetenschap maakte binnen de geesteswetenschappen haar opmars vanaf de jaren tachtig, uitgerekend op het moment dat dit medium gezelschap kreeg van computergerelateerde media. Met andere woorden: academische erkenning komt veelal pas als de grootste bloeiperiode voorbij is en kan dus ook het karakter aannemen van een begrafenis op stand. En dat treft ook nu, want de journalistiek maakt op dit moment, zo zullen we verderop betogen, wellicht de grootste crisis uit haar bestaan door.

\section{Voorspelde veranderingen}

Het voordeel van de huidige crisis in de journalistiek en de dagbladpers is althans dat eerder voorspelde veranderingen eindelijk serieus genomen worden. Ruim twintig jaar geleden, in I988, organiseerde de Stichting Het Persinstituut de conferentie 'De Krant van Morgen. De elektronische toekomst van de schrijvende pers'. Voor mij, als medeorganisator van deze dag, vormde deze conferentie de opmaat tot een project over de toekomst van de journalistieke professie dat bijna tien jaar later met een proefschrift werd afgesloten (Bardoel, I997). Nu ik me tien jaar later opnieuw met dit onderwerp inlaat, is het om te beginnen interessant twintig jaar terug te blikken. Herlezing van het boekverslag van die dag - in de bibliotheek niet meer te vinden, maar dankzij internet nog steeds te raadplegen (Bardoel, i989) - laat zien dat de onderzoekers toen al heel aardig de toekomst die nu realiteit wordt, voorspeld hebben. Maar evenzeer wordt duidelijk dat de betrokkenen uit de perssector zelf de komende veranderingen niet onder ogen wensten te zien.

In het academische kamp voorspelde hoogleraar Jan van Cuilenburg het einde van de 'productlevenscyclus' van de krant en de aflopende exclusiviteit van de journalistiek. Journalist en onderzoeker Ben van Kaam sprak over de 'faxkrant' en 'pc-krant' die zich tot nieuwe massamedia zouden ontwikkelen. Deze door hem omschreven prototypen passen achteraf gezien tamelijk nauwkeurig op nieuwe toepassingen als de e-reader of iPad respectievelijk internetnieuwssites. Ikzelf, toen deeltijdonderzoeker bij Het Persinstituut, zag een nieuwe, derde mediale communicatievorm opdagen tussen directe en massacommunicatie in, met interactiviteit als voornaamste kenmerk. Daardoor zouden allerlei nieuwe afstemmingsmogelijkheden tussen aanbieder en gebruiker ontstaan, waardoor het publiek meer keuze en de journalistiek meer concurrentie zou krijgen.

Tegenover al deze academische nieuwlichterij beleden de sprekers uit de perssector hun ongebroken geloof in de kracht van het gedrukte woord. Krantendirecteur Kees 
Spaan nam nadrukkelijk afstand van 'de al te gemakkelijke parallel tussen krant en beeldscherm, inkt en fluorescerende lettertekens. Die parallel gaat voorbij aan de wezenlijke relatie tussen consument en product, de lezer en zijn dagblad. De pagina's van bijvoorbeeld De Avonden van Gerard Reve zijn via het beeldscherm te consumeren, maar ik zal niet volhouden dat ik dan een boek heb gelezen.' En Trouw-hoofdredacteur Jan Greven meende dat de toekomst van de krant als gedrukt product lag in de aansluiting bij een lezersgemeenschap in een maatschappij waarin veel van wat vroeger voor onderscheid zorgde verdwenen is. En het is bovendien een prachtig idee dat zo'n krant gewoon op de fiets bezorgd wordt.'

Dit debat illustreert dat pers en journalistiek een transitie doormaken van de oude industriële naar een nieuwe netwerkomgeving. In mijn essay Beyond Journalism (Bardoel, I996), stelde ik de vraag of de journalistiek overbodig zou worden wanneer zij ophoudt een onvermijdelijke schakel in de maatschappelijke communicatie te zijn. Daarbij wees ik op de oceaan aan informatie die dankzij nieuwe netwerken beschikbaar komt en daarmee op de toename in interactiviteit en van horizontale communicatie in de samenleving - dit alles ten koste van de verticale communicatie waarin traditionele intermediairs, zoals politieke partijen en journalisten, de hoofdrol speelden. Ook andere ontwikkelingen zoals globalisering, de erosie van de natiestaat en de opkomst van een postmoderne cultuur met meer prioriteit voor populaire cultuur en commercie zouden, zo stelde ik, de positie van de journalistiek verder ondermijnen. Anderzijds zou door deze overvloed aan informatie de behoefte aan gemeenschappelijke oriëntatie en debat en daarmee aan intermediaire kaders niet verdwijnen.

Aanhakend bij Habermasiaanse noties over een discursieve publieke sfeer voorspelde ik dat de journalistiek als klassiek eenheidsberoep zou differentiëren in enerzijds een 'oriënterende journalistiek' die oriëntatie biedt aan een algemeen publiek en anderzijds een 'instrumentele journalistiek' die functionele en specialistische informatie verzamelt voor geïnteresseerde klanten.

'Journalism evolves from the provision of facts to the provision of meaning. In the new ocean of information 'navigation' is needed desperately. Information is less important than shared information. Communication becomes the key-word, not information, and journalists have a long tradition in bringing minds together. In fulfilling this function the - higher educated - public expects the journalist to put aside all traces of old-fashioned paternalism.' (Bardoel, I996: 297)

Terugkijkend op twee decennia prognoses kunnen we constateren dat de richting juist was, maar ook dat de ingrijpendheid van de veranderingen eerder onder- dan overschat is. Wie had eerder de overdonderende opmars van het internet en, in hetzelfde spoor, van gratis informatie durven voorspellen, laat staan het tempo waarin de emancipatie van het publiek zijn beslag zou krijgen? Intussen evenaart de oplage 
van gratis kranten die van betaalde exemplaren, en op internet lijkt gratis nieuws de norm geworden, hoewel er recent weer meer 'paywalls' worden opgeworpen. Verder valt me op dat destijds het denken nog te veel een institutionele focus bezat, met het accent op de bestaande kaders van de gevestigde media en professies. Hoewel voorspeld werd dat de nieuwe informatievoorziening interactiever, eerder horizontaal dan verticaal zou zijn, met meer ruimte voor de burger en navenant minder vrijheidsgraden voor de paternalistische professional, zijn niettemin de empirische en normatieve implicaties van wat ik in 1997 aanduidde als de mediatisering van het maatschappelijk middenveld schromelijk onderschat. Evenmin hebben we voorzien dat voor het beheersen van de informatieovervloed niet zozeer oude en nieuwe informatieprofessionals - van oude journalisten tot nieuwe informatiemakelaars zouden worden ingezet, maar veeleer artificiële intelligentie in de vorm van navigatie- en aggregatiesoftware en zoekmachines. De burger blijkt meer zelfredzaam dan we indertijd veronderstelden en ligt bovendien minder wakker van voorspelde risico's als de informatiekloof en sociale isolatie.

\section{Netwerkjournalistiek}

Wat betekent dit alles voor de trotse professie voorheen bekend als journalistiek? Het is al gezegd, de journalistiek verkeert in een ernstige crisis, wellicht de meest ernstige in haar bestaan. Er is sprake van een dubbele crisis, enerzijds door de snelle opmars van computergerelateerde media (internet) die afbreuk doet aan het debiet van bestaande media en anderzijds door een grote economische crisis die het extra lastig maakt om de omslag naar nieuwe platforms en verdienmodellen te maken. Nog nooit zijn er in zo korte tijd zoveel debatten, publicaties en adviescommissies (cf. Brinkman, 2009; Ummelen, 2009) gewijd aan een professie die eerder nooit opviel door veel externe bemoeienis of interne reflectie. Bij nader bezien is de huidige crisis in de journalistiek het gevolg van zowel de evoluerende technologie als van een veranderde samenleving.

Wat betreft de eerste ontwikkeling: de technologie die traditioneel een belangrijke bondgenoot van de journalistiek was, wordt nu een geduchte tegenpool. Journalistiek werd pas een afzonderlijke professie in de tweede helft van de negentiende eeuw, dankzij de opkomst van de industriële massapers. Toen ontstonden er grote mediaorganisaties met een duidelijke arbeidsverdeling tussen uitgever en journalist, waarin de laatste los van de commerciële context zich een maatschappelijke verantwoordelijkheid ging aanmeten om het publiek adequaat te informeren. Later opgekomen media als de radio en de televisie ontwikkelden gaandeweg eigen vormen van journalistiek, maar tot op de dag van vandaag bleef de dagbladjournalistiek zowel kwantitatief als kwalitatief de moeder en de hoeder van de professie. Momenteel maakt deze traditionele industriële journalistiek, die verbonden is met grote media-instellingen en centrale redacties met een eigen nieuwscultuur, de omslag naar een nieuwe, gedecentraliseerde 'netwerkjournalistiek' (Bardoel \& Deuze, 
200I). Deze nieuwe vorm van journalistiek zou moeten inspelen op de voornaamste kenmerken van de nieuwe media: interactiviteit, multimedialiteit en hypertekstualiteit.

Al begin jaren tachtig voorzagen twee leden van de toenmalige Mediaraad, hoogleraar telecommunicatie Bordewijk en journalist Van Kaam (I982), de opmars van consultatiemedia ten koste van de bestaande allocutiemedia. Intussen heeft zich onder mediagebruikers het schisma voltrokken: oudere generaties halen hun actuele informatie vooral nog bij de oude allocutieve media als het dagblad en de omroep, terwijl jonge generaties hun informatie vooral zelf actief en interactief bijeengrazen via internet en gratis media. Aan deze nieuwe informatieplatforms komen echter steeds minder journalisten te pas. Voor een professie die gewend was zelf te bepalen wat voor het publiek van belang is, betekent dit een grote omschakeling. De recente opmars van burgergeoriënteerde journalistiek - voor burgers ('civiele journalistiek') of door burgers ('burgerjournalistiek') - kan rustig gezien worden als een revolte tegen een elitaire en bevoogdende professie.

De multimedialiteit die dankzij digitalisering mogelijk wordt, gooit niet alleen de bestaande verhoudingen ter redactie overhoop, maar meer nog de maatschappelijke informatievoorziening als geheel. Voor redacties betekent multimediaproductie dat de nieuwsgaring en -productie veelal niet meer voor de verschillende mediaplatforms afzonderlijk plaatsvindt, maar wordt geïntegreerd of thematisch ingedeeld. Vanuit een gezamenlijk verzorgde redactionele database vindt vervolgens bewerking plaats voor de specifieke mediaplatforms met elk hun eigen eisen qua tekst- en beeldbewerking. De komst van internet brengt zo voorheen gescheiden mediavelden bij elkaar en maakt alle typen informatievoorziening, ongeacht herkomst of doel, via een enkel medium - als we internet een medium mogen noemen - voor iedereen beschikbaar. Hypertekstualiteit is indertijd als trefwoord gekozen om aan te duiden dat in een geconvergeerde mediaomgeving informatie van verschillende aard - tekst, beeld en geluid - op diverse wijze - in lagen en paletten geordend, met voortdurende doorverwijzingen en meta-informatie - wordt aangeboden. De convergentie van oude en nieuwe communicatiemodaliteiten heeft daarmee niet alleen ingrijpende structurele effecten (fusie van media, reorganisatie van redacties) maar evenzeer ingrijpende inhoudelijke en esthetische gevolgen voor de manier waarop (multi)media hun verhaal vertellen.

Met dit alles wordt het internet de centrale agora van de postmoderne samenleving, zowel in de zin van mondiale ontmoetingsplaats als van marktplaats. In deze onbegrensde context wordt het voor journalisten en media steeds moeilijker om een eigen niche af te bakenen.

Naast de technologische evolutie, door Deuze (2005) kortweg aangeduid als multimedialisering, hebben maatschappelijke ontwikkelingen hun weerslag op de journalistiek, door hem getypeerd als multiculturalisering. De reden dat de beschreven 
snel konden doorzetten, heeft alles te maken met de omstandigheid dat de sociologische basis voor deze omslag allang voorhanden was. De individualisering die zich op alle maatschappelijke terreinen al decennia als dominante trend manifesteerde, werd binnen de media afgeremd doordat de technologie tot dusverre kunstmatige schaarste, collectieve afname en het primaat van de producent dicteerde.

De nieuwe werkelijkheid van permanente verbinding met en toegang tot kennis opgeslagen in kunstgeheugens waar ook ter wereld, verandert de relatie tussen mensen en media op een fundamentele manier: 'The potential for knowledge sharing is unmatched in history. Never before have so many creative and knowledgeable people been connected by such an efficient, universal network' (Gruber, 2008: 4). Volgens Brants (2007: 107) leidt een toenemende 'orientation towards consuming and materialising personal desires' ertoe dat het publiek nieuws, politiek en publieke goederen vanuit een instrumentele instelling gaat benaderen, waardoor het vermogen van media om sociale cohesie, collectieve waarden en consensus te organiseren, wordt ondergraven. Deze individualisering en ontideologisering van de mediaconsumptie past ook in de ontwikkeling van moderniteit naar postmoderniteit. Pavlik (200I) spreekt in dit verband van een 'fluid and volatile journalism', Deuze (2008) houdt het op 'liquid journalism', een vloeibare journalistiek die moet kunnen omgaan met, zoals hij het met Baumann uitdrukt, 'an increasingly complex and liquid modern society' (Deuze, 2005: 455). Internet slecht de barrières van plaats en tijd en voor de jongste generaties zijn niet traditionele media maar Google en Apple de belangrijkste poortwachters naar de buitenwereld geworden.

\section{Erosie van een professie}

Deze toenemende onbegrensdheid van openbare communicatie, naar plaats, tijd en modaliteit, treft de journalistieke professie in het hart. Allerwegen voorzien omstanders de erosie van de journalistieke professie, maar de afstandelijke blik van de academische buitenstaander levert opnieuw een ander, genuanceerder beeld op. Naar mijn idee wordt de journalistiek nu eindelijk wat zij altijd al wilde zijn, of zei te willen zijn: een open professie zonder een claim op exclusiviteit in een eigen domein, zonder de strikte afbakening van een eigen discipline en methodiek, zonder de eis tot vooropleiding en permanente bijscholing maar met duidelijke opvattingen over haar maatschappelijke verantwoordelijkheid en ethiek. In de praktijk was de journalistieke werkwijze evenwel lang niet zo kwetsbaar als zij zichzelf voordeed. De professie werd immers afgeschermd door de Berlijnse muren van de mediaorganisatie, een collectieve redactiecultuur en door formele afspraken over de scheiding tussen redactie en directie en de verplichting van redactiestatuten. 
Met de overgang van industriële naar netwerkjournalistiek worden deze traditionele media-instituties met bijbehorende beschermingsarrangementen - die overigens door teruglopende rendementen en nieuwe eigenaren buitengewoon broos blijken minder belangrijk en wordt de journalist als een echte professional steeds vaker een kleine zelfstandige. Hierdoor volstaat het niet langer de kennis en kunde van de professie collectief aan te brengen, maar wordt het wenselijk deze individueel te verankeren. Journalisten krijgen aldus een koekje van eigen deeg voorgezet; nu de beschermende afgrenzingen van traditionele media eroderen, ervaart men eindelijk wat het betekent om tot een open beroep te behoren.

'Nadat de journalist zich eerder onder de noemer "professionalisering" bevrijd heeft van het primaat van ideologische prerogatieven, [maakt] het publiek zich op zijn beurt onder het motto "individualisering" voor een deel los van het journalistiek leiderschap. Daardoor verschuiven de verhoudingen tussen aanbieder en afnemer; de oude, vertrouwde relatie verandert in een nieuw, zakelijk arrangement en er vindt een "nieuwe ontvoogding" plaats. Omdat de journalist en het journalistiek product concurrentie ondervinden van andere diensten en communicatieberoepen zullen zij een sterker bewustzijn van eigen profiel en positionering moeten ontwikkelen.' (Bardoel, I993: 145)

Daarvoor is het nodig dat journalisten hun per traditie defensieve houding ten opzichte van veranderingen in het vak laten varen en kiezen voor een meer offensieve en zelfbewuste koers.

\section{Profiel gevraagd}

Juist in een multimediale omgeving zal een open professie zich moeten bezinnen op haar taak en profiel en op de mate van onderscheidendheid ten opzichte van andere informatieaanbieders. De journalistieke professional wordt onderdeel van veel meer verschillende bemiddelingspraktijken, van grote en kleine media, met heel diverse verdienmodellen waarin oude afspraken en conventies niet langer gelden. De positie van eigenaars en adverteerders wordt sterker en de journalistieke onafhankelijkheid staat over de hele linie onder druk. In een recent nummer van dit tijdschrift geeft José van Dijck (20I0) een aardige vlootschouw van het nieuwe speelveld. Ook volgens haar neemt de druk op de journalistieke onafhankelijkheid toe en vergt de migratie naar een digitale omgeving een scherpere profilering van het eigen journalistieke merk. Mediaorganisaties zullen, teneinde de publieke functie van journalistiek als een onafhankelijke professie te waarborgen, meer duidelijkheid moeten creëren naar hun gebruikers. Journalisten kunnen niet langer volstaan met de 'meesters van het moment' te zijn (Eide, 2007: 27). 
De grote vraag blijft in hoeverre de journalistiek in staat zal zijn zich in een open omgeving te handhaven, nu internet zorgt voor hybridisering en vervaging van de grenzen van de professie. Bird (2009: 295) denkt dat een goed functionerende democratie nieuwsorganisaties nodig heeft die professionele journalisten in dienst hebben die nieuwe informatie genereren en niet alleen maar bestaande informatie rondpompen. Zij gaat er echter aan voorbij dat deze nieuwsorganisaties de nieuwe technologie voorlopig vooral aangrijpen om kosten te besparen door kleinere rompredacties te vormen, met uitbesteding van een groot deel van de productie. Naarmate nieuwsorganisaties verkruimelen en een zelfstandige beroepspraktijk couranter wordt, moet de journalistieke identiteit minder in de organisatie en meer in de individuele professional verankerd worden.

'The fundamental challenge that online journalists pose for journalists in traditional media', aldus Jane Singer (2003: I39), 'is not about money or even job security. It is about the notion of professionalism.' Daarom stelt zij dat journalisten hun positie als professional moeten versterken, 'establish[ing] a monopoly on expertise that makes them irreplaceable' (idem, I4I). Stephens (2007: 35) is nog stelliger: 'What is required - if journalism is to move beyond selling cheap, widely available, stalerthan-your-muffin news - is, to choose a not very journalistic sounding word, wisdom.' Deuze (2005: 455) voegt hieraan toe dat bij professionaliteit ook een toenemende transparantie en 'more responsive, interactive and inclusive journalistic practices' horen. De controle op de accuraatheid en relevantie van de geleverde informatie hoeft niet meer exclusief door een redactie te gebeuren, maar kan ook plaatsvinden in het kader van open source productie op basis van online conversatie met het publiek (cf. Reese et al., 2007) of door peer recommendation via sociale netwerken. Journalistiek wordt aldus meer een open keuken, en naarmate de maker zelfverzekerder is over zijn capaciteiten zal hij ook minder moeite hebben met zo'n kijk in de keuken en met interactie met zijn publiek. Toenemende transparantie kan ook helpen om de tanende geloofwaardigheid van de journalistiek tegen te gaan.

Expertise, wijsheid, transparantie, het zijn aantrekkelijke termen om het professionele profiel van de journalistiek aan te scherpen, maar tegelijkertijd zijn ze nogal vaag, net zoals oude trefwoorden als objectiviteit en onafhankelijkheid. In de journalistieke praktijk fungeren ze vooral als bezweringsformules die meestal het einde, en niet het begin, van de discussie markeren. In de toenemende snelheid en onzekerheid waarin journalisten als waterdragers van de actualiteit werken, kiezen ze er te vaak voor om zich vast te klampen aan elkaar en aan de veronderstelde eisen van het medium, uitmondend in hypes, pack journalism en medialogica (Vasterman, 2004). Goede journalistiek wordt hierbij naar de achtergrond gedrongen, letterlijk en figuurlijk, en zij zal van deze zwakte haar kracht moeten maken door meer te duiden en eigen onderzoek te doen. Tegelijk moet men zich daarbij voortdurend realiseren dat burgers voor deze diensten uiteindelijk, ongeacht het verdienmodel, 
moeten willen betalen. Wanneer de journalistiek positie verliest als primaire informatiebron dient ze aan belang te winnen als second opinion.

Als alle helpers - technologie, organisatie, redactie - verdwijnen en de professional meer op zichzelf aangewezen wordt, moet hij zelf zijn professie opnieuw uitvinden en beter afgrenzen: wat zijn haar onderscheidende taken en hoe kan zij deze het meest geloofwaardig uitvoeren? In de nieuwe open omgeving moet de journalistieke opdracht scherper afgebakend worden, zoals de empirische opgave van het achterhalen van de waarheid in de actuele werkelijkheid en de normatieve taak van het organiseren van het maatschappelijk debat in een democratische samenleving. Naast herbezinning op de doelstellingen moeten ook de journalistieke werkwijzen en kerncompetenties beter doordacht en explicieter verantwoord worden. Ter vergelijking: ondanks alle discussie bestaat er zoiets als een wetenschappelijke methode, waarnaar in onderzoeksartikelen verwezen wordt, maar bestaan er ook expliciete en alom erkende journalistieke methoden? Deze nieuwe nadruk op professionaliteit stelt uiteraard ook hogere eisen aan het journalistieke onderwijs en onderzoek, waaronder academisering van het journalistiek onderwijs en meer aandacht voor journalism studies. En hiermee zijn we weer terug bij het begin van deze bijdrage.

\section{Literatuur}

Bardoel, J. (red.) (1989). De Krant van Morgen. De elektronische toekomst van de schrijvende pers. Amsterdam: Stichting Het Persinstituut.

Bardoel, J. (I993). Zonder pen of papier. Journalistiek op de drempel van een nieuwe eeuw. Amsterdam: Otto Cramwinckel Uitgever.

Bardoel, J. (1996). Beyond Journalism. A profession between Information Society and Civil Society. European Journal of Communication I996 (II) 3, pp. 283-303.

Bardoel, J. (I997). Journalistiek in de informatiesamenleving. Amsterdam: Otto Cramwinckel Uitgever.

Bardoel, J. \& Deuze, M. (200I). 'Network Journalism' : Converging Competences of Old and New Media Professionals, Australian Journalism Review 23 (2): 9I-IO3.

Bardoel, J., Vos, C., Vree, F. van \& Wijfjes, H. (red.) (2002/2005). Journalistieke Cultuur in Nederland. Amsterdam: Amsterdam University Press.

Bird, S.E. (2009). The future of journalism in the digital environment. Journalism Io (3): 292-295.

Bordewijk, J.L. \& Kaam, B. van (1982). Allocutie: enkele gedachten over communicatievrijheid in een bekabeld land. Baarn: Bosch \& Keuning.

Brants, K. (2007). Changing Media, Changing Journalism. In: Meier, W.A. Q J. Trappel (eds). Power, Performance Q Polititics; Media Policy in Europe. Baden-Baden: Nomos, pp. I05-I23.

Buijs, K. (2008). Journalistieke kwaliteit in het crossmediale tijdperk. Z.P.: Boom

Commissie-Brinkman (2009). De Volgende editie. Den Haag: Tijdelijke Commissie Innovatie en Toekomst Pers.

Deuze, M. (2005). What is Journalism? Professional identity and ideology of journalists reconsidered. Journalism 6 (4): 442-464.

Deuze, M. (2008). The changing context of news work: Liquid journalism and monitorial citizenship. International Journal of Communication, 2, 848-865.

Dijck, J. van (20IO). Professionele identiteit in een digitale omgeving. Een essay. Tijdschrift voor Communicatiewetenschap 38 (I): 5-24.

Eide, M. (2007). Encircling the Power of Journalism. Nordicom Review, Jubilee Issue 2007, pp. 2I-29. 
Gruber, T. (2008). Collective knowledge systems: where the Social Web meets the Semantic Web. Web Semantics: Science, Services and Agents on the World Wide Web, 6 (I): 4-13.

Hemels, J. (1972). De journalistieke eierdans. Over vakopleiding en massacommunicatie. Assen: Van Gorcum \& Comp.

Hermans, L. , Vergeer, M., d'Haenens, L. \& Joniaux, K. (2009). Journalistiek en internet in de Lage Landen. Een vergelijkende studie naar het internetgebruik van Nederlandse en Vlaamse journalisten. Tijdschrift voor Communicatiewetenschap 37 (2): 99-II7.

Pavlik, J. (200I). Journalism and new media, New York, NY: Columbia University Press.

Reese, S.D., Rutigliano, L., Hyun, K. \& Jeong, J. (2007). Mapping the Blogosphere: professional and citizen-based media in the global news arena. Journalism 8 (3): 235-26I.

Singer, J. (2003). 'Who are these guys?' The online challenge to the notion of journalism. Journalism 4 (I): $139-163$.

Stephens, M. (2007). Beyond the News. Columbia Journalism Review January/February 2007, pp. 34-39. Ummelen, B. (red.) (2009). Journalistiek in diskrediet. Nijmegen: Katholiek Instituut voor Massamedia.

Vasterman, P. (2004). Mediahype. Amsterdam: Aksant. 